\title{
Risk of tuberculosis in immigrant Asians: culturally acquired immunodeficiency?
}

\author{
P J Finch, F J C Millard, J D Maxwell
}

\begin{abstract}
Study of the 620 Asian immigrants with tuberculosis notified in the Wandsworth area of south London between 1973 and 1988 showed a bimodal pattern of tuberculosis notifications: in 1977 there was a peak among Asians from East Africa, and in 1981 a peak among those from the Indian subcontinent. There was a mean lag time of five years between clinical presentation and immigration. Logit analysis showed that, although overall more men had tuberculosis than women, glandular tuberculosis was more common among women of all groups, and pulmonary tuberculosis was more common among Hindu women than Hindu men. Both subgroups of Asians had a substantially higher incidence of tuberculosis than white people, particularly at extrapulmonary sites. Hindus were also at a significantly greater risk of tuberculosis at all sites than Muslims (Hindu:Muslim risk ratio 5.5 for women and 3.7 for men). The increased susceptibility to tuberculosis of Hindus, particularly Hindu women, may be related to a culturally acquired immunodeficiency caused by vegetarianism and associated vitamin deficiency.
\end{abstract}

Asians in Britain have a greater risk of developing tuberculosis than the indigenous population. ${ }^{1}$ National surveys of tuberculosis notifications in 1983 show that over a third of all new cases in England and Wales were in people from the Indian subcontinent. ${ }^{2}$ Data were presented separately for immigrants from Pakistan and India, but no analysis of risk according to other Asian subgroups has previously been attempted.

Asians are a heterogeneous group with ethnic, cultural, and religious differences. ${ }^{34} \mathrm{We}$ have been impressed by the number of Hindu patients with tuberculosis in our chest clinic. In prospective studies of Asian outpatients, we have found that vitamin $\mathrm{D}$ deficiency was much more common among Hindu Asians, most of whom were vegetarians, ${ }^{5}$ and we were impressed by the number of Hindu patients with osteomalacia who have a past history of tuberculosis.

We therefore undertook an analysis of the characteristics of Asian patients with tuberculosis in the Wandsworth area of London, taking particular note of the effect of origin, migration, sex, and religion. We attempted to determine whether there was an excess of Hindu patients with tuberculosis in this area, and if so whether this was due to a local concentration of Hindus in the community or an increased risk in this religious subgroup.

\section{Methods}

PATIENTS

We reviewed the records of all patients diagnosed as having tuberculosis at the chest clinic at St James's Hospital, Balham, from 1973 to 1988. The chest clinic served the two district general hospitals (St George's and St James's Hospitals) in the Wandsworth area of south London, an area virtually coterminous with the Wandsworth Health Authority area. Information about these patients had been collected prospectively, by interviewing all index patients, by the same specially trained chest clinic clerk from 1973 to 1980 , and by the same chest clinic health visitor from 1980 to 1988 . A standard set of questions, including some relating to country of origin and duration of residence in Britain, were asked and the data recorded on punched cards at the time of diagnosis; the same chest consultant (FJCM) supervised the data collection throughout the 15 year period.

We selected records of all Asians with tuberculosis who had emigrated to Britain from India, Pakistan, and East Africa with all white patients with tuberculosis born in the United Kingdom for comparison. The country of residence immediately before immigration into Britain was taken as the country of origin. Other racial groups and second generation Asians were excluded from this study. The Asian patients were grouped by religion-Hindu, Muslim, and other (for example, Christian and Sikh)-by inspection of their names by an experienced Asian dietitian, who was unaware of our test hypothesis. Only the Hindu and Muslim patients were used in the subsequent analyses as the numbers of patients of other religions were very small.

An attempt was made to establish the diagnosis of tuberculosis in all cases, by examination of sputum by direct smear and culture for pulmonary tuberculosis and by histological examination and culture of lymph nodes and specimens from other organs for extrapulmonary tuberculosis. The principal site of the tuberculosis was documented as follows: pulmonary-parenchymal lung disease with or without hilar lymphadenopathy; glandularinfection of peripheral or hilar nodes without 
parenchymal lung disease; other-any other site.

The patient's age, date of entry to Britain, and country of origin were noted.

\section{LOCAL DEMOGRAPHIC STATISTICS}

Incidence rates were calculated after estimation of the white and Asian populations in the 16 wards that comprise the Wandsworth Health Authority area on the basis of the "small area statistics" of country of origin in the 1981 population census. Individuals with a head of household born in the United Kingdom were used to estimate the white population, and those individuals born in India, Bangladesh, Pakistan, and East Africa were used to estimate the Asian population. An estimate of the ratio of Hindus to Muslims in the Wandsworth area was derived from Hospital Activity Analysis data on the religion of all hospital patients discharged and day patients attending St George's Hospital in the 1988 financial year, obtained from the Patient Administration System. Validation of this ratio was carried out by performing a metaanalysis of published population statistics according to country of origin.

\section{STATISTICS}

Confidence intervals for risk ratios for tuberculosis at different sites in the white and Asian groups were calculated as described by Morris and Gardner, ${ }^{6}$ and a meta-analysis of binomial proportions of Indian and Pakistani Asians was performed to validate our proportion of Hindus and Muslims according to the methods described by Gardner and Altman. ${ }^{7}$

The Statistical Package for Social Sciences (SPSS) was used for multivariate analysis and for logit analysis. Multivariate analysis of variance and covariance (MANOVA) was used to study the effect of religion and country of origin on the length of time the Asian group had been in Britain. Logit analysis (LOGLINEAR) was used to study the effects of sex differences on the incidence of tuberculosis at different sites in the white, Hindu, and Muslim groups. This allows analysis of tables of frequencies (as the logarithms of the actual frequencies) cross tabulated by more than two factors (analogous to the $\chi^{2}$ analysis for a simple two factor table). Some factors included may not have a significant effect on the results, and logit analysis enables the fitting of a statistical model to describe the observed frequencies, using only those factors or interactions of factors shown to be significant. Estimates of the odds ratio derived from each factor or interaction included in the model can also be calculated.

\section{Results}

In all, 432 UK whites and 620 immigrant Asians (420 Hindu, 151 Muslim, and 49 of other religions) were diagnosed as having tuberculosis during the 15 years studied. The diagnosis of pulmonary tuberculosis was confirmed by culture or by direct smear in $86 \%$ of cases. Extrapulmonary tuberculosis was confirmed by culture or histological examination in $87 \%$ of cases. In 144 of the 1052 patients tuberculosis was thought the most likely diagnosis by the clinician without bacteriological or histological evidence.

\section{ASIAN POPULATION OF WANDSWORTH}

The population of the Wandsworth Health Authority area, as derived from the 1981 census "small area statistics," is shown in table 1 , with the Patient Administration System sample for the 1988 financial year. The proportion of Asians who were Hindus was 0.384 (95\% confidence interval (CI) $0.363-0.405)$ and from this we estimated there to be around 3800 Hindus and 6000 Muslims in Wandsworth. Table 1 also shows that the mean age of the patient sample population from St George's Hospital was similar to that of the Wandsworth area population, and that the estimated male:female ratios for whites, Hindus, and Muslims in Wandsworth $(0.92,1.0,1.13)$ were very similar to the UK population sex ratios of $0 \cdot 95,1 \cdot 01$, and $1 \cdot 14 .^{8}$

The assumption that the ethnic proportions in the community were constant throughout the 15 years of the study was validated by a meta-analysis of estimates of Asians in Britain, by country of origin, from 1971 to 1986 from published data of the Office of Population Censuses and Surveys. ${ }^{8-11}$ The proportion of Indian Asians did not alter significantly during this time either for the total Asian population $\left(\chi^{2}=8 \cdot 3, v=5\right)$ or for the immigrant Asian population $\left(\chi^{2}=4 \cdot 6, v=3\right)$. From this metaanalysis estimates of $0.616(95 \%$ CI 0.614 $0.619)$ and $0.629(95 \% \mathrm{CI} 0.627-0.632)$ respectively were obtained for the proportion of Asians from India. The figure for Asian immigrants from India in the Wandsworth area in 1981 was $0.629(95 \%$ CI $0 \cdot 617-0 \cdot 641)$.

Table 1 Population numbers (mean age) and male:female ratio by ethnic group in Wandsworth Area Health Authority $(A H A)$

\begin{tabular}{|c|c|c|c|c|c|c|}
\hline & \multicolumn{4}{|c|}{ Wandsworth $A H A$ population } & \multicolumn{2}{|c|}{ PAS data sample } \\
\hline & All & Male & Female & $M: F$ & Male & Female \\
\hline $\begin{array}{l}\text { Total } \\
\text { UK }\end{array}$ & $\begin{array}{l}185257(40) \\
142287(37)\end{array}$ & $\begin{array}{l}89115 \\
68308\end{array}$ & $\begin{array}{l}96142 \\
73979\end{array}$ & $\begin{array}{l}0.93 \\
0.92\end{array}$ & & \\
\hline $\begin{array}{l}\text { Asian } \\
\text { Hindu } \\
\text { Muslim }\end{array}$ & $\begin{array}{l}9846(35) \\
{[3787]} \\
{[6059]}\end{array}$ & $\begin{array}{c}5108 \\
{[1894]} \\
{[3214]}\end{array}$ & $\begin{array}{r}4738 \\
{[1894]} \\
{[2844]}\end{array}$ & $\begin{array}{l}1.08 \\
1.00 \\
1.13\end{array}$ & $\begin{array}{l}820(32) \\
304(34) \\
516(30)\end{array}$ & $\begin{array}{r}1316(33) \\
526(36) \\
790(30)\end{array}$ \\
\hline
\end{tabular}

Hindu and Muslim numbers in square brackets are calculated from the 1981 census "small area statistics" (SAS) and a data sample from the Patient Administration System (PAS) from St George's Hospital. The SAS figures are for the Tooting, Bedford, Graveney, Balham, Nightingale, Furzedown, Latchmere, St John, Shaftesbury, Northcote, Southfield, Earlsfield, St Mary Park, Fairfield, Springfield, and Queenstown wards. 


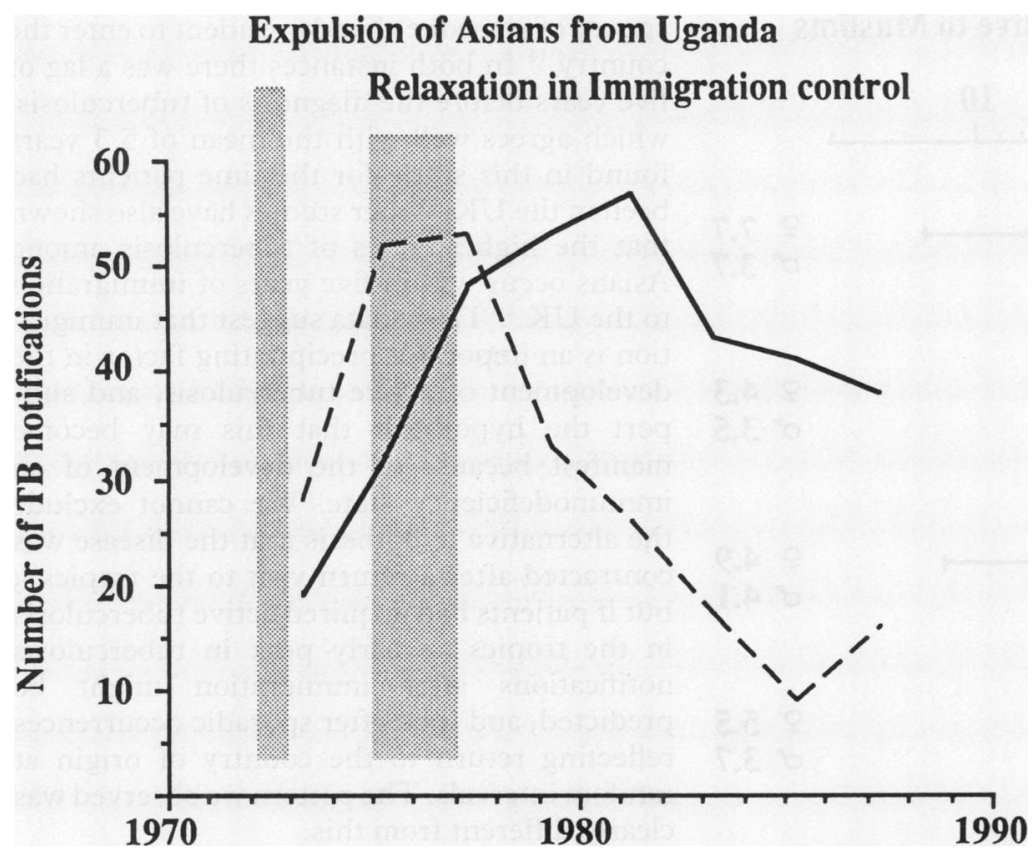

Figure 1 Number of notifications of Asian patients with tuberculosis (TB) in Wandsworth, according to country of origin (dashed line East Africa, solid line Indian subcontinent). The timing of political events thought to have affected the pattern in notifications is also shown.

TIME TRENDS IN TUBERCULOSIS NOTIFICATIONS A bimodal pattern in the number of tuberculosis notifications was observed, with a peak in 1977 among Asians emigrating from East Africa and a peak in 1981 among Asians emigrating from the Indian subcontinent (fig 1). Asian immigrants had been in the UK for a mean of $5 \cdot 3(95 \%$ CI $5 \cdot 0-5 \cdot 5)$ years before their clinical presentation with tuberculosis.

Multivariate analysis showed that the age of the Asian patients correlated positively with their time in Britain before clinical presentation ( $r=0.29,95 \%$ CI $0.21-0.36)$, and that their country of origin but not religion had a significant effect on the time in Britain. Muslims from the Indian subcontinent had been in Britain for slightly longer than other groups (mean 6.2 (95\% CI 5.6-6.9) years). Asian patients were on average some 16 years younger than the white patients but no differences in age emerged between Hindus and Muslims or in relation to different sites of tuberculosis (see table 2).

Table 2 Annual incidence of tuberculosis per 100000 of population in Wandsworth, mean age, and male:female (M:F) sex ratio for each group, by site of tuberculosis and religious group (pooled data 1973-88)

\begin{tabular}{|c|c|c|c|c|}
\hline & Pulmonary & Glandular & Other & All \\
\hline $\begin{array}{l}\text { HINDU } \\
\text { Incidence } \\
\text { Mean age } \\
\text { M:F ratio }\end{array}$ & $\begin{array}{c}352.0 \\
44 \\
1.04\end{array}$ & $\begin{array}{c}272 \cdot 8 \\
46 \\
0 \cdot 68\end{array}$ & $\begin{array}{c}114.4 \\
46 \\
1.83\end{array}$ & $\begin{array}{c}739 \cdot 2 \\
45 \\
0.97\end{array}$ \\
\hline $\begin{array}{l}\text { MUSLIM } \\
\text { Incidence } \\
\text { Mean age } \\
\text { M:F ratio }\end{array}$ & $\begin{array}{l}71 \cdot 5 \\
45 \\
2 \cdot 42\end{array}$ & $\begin{array}{l}68 \cdot 2 \\
46 \\
0 \cdot 94\end{array}$ & $\begin{array}{l}26 \cdot 4 \\
48 \\
2 \cdot 43\end{array}$ & $\begin{array}{c}166 \cdot 2 \\
46 \\
1 \cdot 60\end{array}$ \\
\hline $\begin{array}{l}\text { CAUCASIAN } \\
\text { Incidence } \\
\text { Mean age } \\
\text { M:F ratio }\end{array}$ & $\begin{array}{l}17 \cdot 1 \\
62 \\
2 \cdot 16\end{array}$ & $\begin{array}{c}1 \cdot 8 \\
58 \\
0.58\end{array}$ & $\begin{array}{c}1 \cdot 3 \\
64 \\
1.00\end{array}$ & $\begin{array}{l}20 \cdot 2 \\
62 \\
1 \cdot 81\end{array}$ \\
\hline $\begin{array}{l}\text { ALL } \\
M: F \text { ratio }\end{array}$ & $1 \cdot 71$ & 0.72 & 1.66 & $1 \cdot 36$ \\
\hline
\end{tabular}

\section{INCIDENCE OF TUBERCULOSIS}

In each of the 15 years studied there was a similar excess of Hindus over Muslims in incidence of tuberculosis. The data from the whole period were thus pooled for analysis. The annual incidences of tuberculosis for all three groups are shown in table 2. Both Hindus and Muslims presented with more extrapulmonary tuberculosis than white people, but the difference was most striking for Hindus; the risk ratios of tuberculosis by site for Hindus relative to Muslims are shown in figure 2. Hindu men and women alike had risk ratios that were significantly greater than unity for tuberculosis at all sites, the highest risk ratio $(7 \cdot 7)$ being for Hindu women with pulmonary tuberculosis. After allowance had been made for religion, country of origin had no independent effect on the incidence or pattern of tuberculosis.

EFFECTS OF SEX ON THE INCIDENCE OF TUBERCULOSIS

There were substantial differences in sex ratio between the religious groups and for the different sites of tuberculosis. To explore these differences further, we fitted a logit model to the numbers of tuberculosis notifications cross tabulated by site of tuberculosis, religion, and sex, comparing these with the calculated male and female numbers.

A fully saturated model (that is, one containing all possible factors and interactions) was required to describe the data adequately. Sex ratios significantly greater than unity (indicating a greater risk for men than for women) were found for tuberculosis overall $(1 \cdot 2,95 \% \mathrm{CI}$ $1 \cdot 1-1 \cdot 4)$, for pulmonary tuberculosis $(1 \cdot 5,95 \%$ CI 1.2-1.8), and for Muslims (1·3, 95\% CI 1.1$1 \cdot 6)$, and ratios significantly less than unity (indicating a greater risk for women than for men) were found for glandular tuberculosis $(0.6,95 \%$ CI $0.5-0.8)$ and pulmonary tuberculosis in Hindus $(0 \cdot 7,95 \%$ CI $0.5-0.9)$.

\section{Discussion}

Asian immigrants are a culturally diverse group. As culture and lifestyle are known to have important consequences for health, we were interested to explore whether such cultural differences among Asians, in particular those consequent on major religious differences, might affect susceptibility to tuberculosis.

In this study we identified the religion of Asians by their names. This is accepted as a reliable method of identifying religion among Asians, ${ }^{12}$ and has been implemented by others. ${ }^{1}$ The Hindu family name (for instance, Patel, Bhatia, Thakkar) is quite characteristic of a particular subdivision of a caste-indeed, it indicates the person's social status and traditional occupation-and Muslim names can readily be recognised by the religious name preceding the personal name (for instance, Mohammed, Abdul, Syed, or any of the 99 names of Allah).

The method of deriving population estimates of Hindus and Muslims in the locality is open to criticism because one group 
Risk of TB for Hindus relative to Muslims

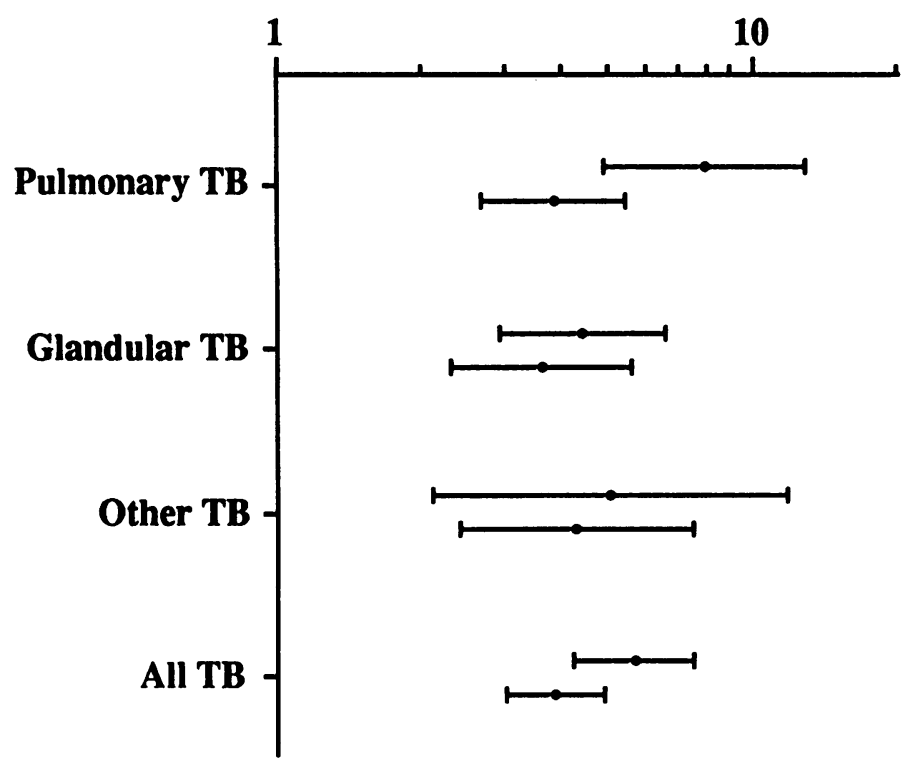

9 7.7

or 3.7

\& 4.3

or 3.5

\% 4.9

on 4.1

\&5.5

ơ 3.7

Figure 2 Risk of tuberculosis (TB) (with 95\% confidence intervals) for Hindus relative to Muslims according to site of tuberculosis for women and men. The scale is logarithmic. spouse of someone already resident to enter the country. ${ }^{14}$ In both instances there was a lag of five years before the diagnosis of tuberculosis, which agrees well with the mean of $5 \cdot 3$ years found in this study for the time patients had been in the UK. Other studies have also shown that the highest rates of tuberculosis among Asians occur within five years of immigration to the UK. ${ }^{15}$ These data suggest that immigration is an important precipitating factor in the development of active tuberculosis, and support the hypothesis that this may become manifest because of the development of an immunodeficiency state. We cannot exclude the alternative hypothesis that the disease was contracted after a return visit to the tropics ${ }^{16}$; but if patients had acquired active tuberculosis in the tropics an early peak in tuberculosis notifications after immigration might be predicted, and thereafter sporadic occurrences reflecting return to the country of origin at random intervals. The pattern we observed was clearly different from this.

The strikingly increased risk of tuberculosis, particularly at extrapulmonary sites, for Hindu Asians, has not been previously recognised, and is as yet unexplained. It cannot be attributed to social class, as Asian immigrants in the UK are more likely to be in social classes I and II than native white people ${ }^{17}$ and Asian patients come from an economically privileged section of our community: the national housing and dwelling survey in $1978^{18}$ showed that Asians in Wandsworth had higher proportions of professional, non-manual, and self employed individuals and of owner occupiers of dwellings than any other ethnic group. Cultural factors may be relevant and a major difference between Hindus and Muslims is in their diet.

Traditionally Hindus are vegetarians; in prospective studies we have shown that at least half of the Hindus in the Wandsworth area are vegetarians, compared with fewer than $1 \%$ of Muslims. ${ }^{13}$ A postal study of Asians in north London showed a prevalence of tuberculosis $2 \cdot 8$ times higher among strict vegetarians than among those taking a mixed diet, leading the authors to conclude that dietary factors were of major importance in determining susceptibility to tuberculosis. ${ }^{19}$ It was also suggested that iron or vitamin B12 deficiency may account for the susceptibility to tuberculosis, on the basis of in vitro studies showing impaired neutrophil function in cobalamin depleted individuals, ${ }^{20}$ though it is recognised that macrophages and lymphocytes rather than phagocytes are concerned in the host defence against tuberculosis. ${ }^{21}$

This study of 620 Asian immigrants with tuberculosis strongly supports the view that a vegetarian diet is a risk factor because the Hindus (who comprise the majority of Asian vegetarians) were at the greatest risk. We have no direct evidence on the specific factor or factors in the diet that might be responsible, but circumstantial evidence suggests that vitamin D deficiency may play a part. Vegetarian (Hindu) Asians are known to be more likely to suffer from osteomalacia ${ }^{22}$ and rickets $^{23}$ and to have lower concentrations of accounted for $43 \%$ of all immigrants to the United Kingdom. ${ }^{14}$ The peak in immigrants from the Indian subcontinent in 1981 may be attributed to changes in immigration control between 1974 and 1977, which allowed the 
25-hydroxyvitamin D. ${ }^{24}$ The lag of five years after immigration to the UK before clinical presentation with tuberculosis, similar to the interval before development of osteomalacia, suggests that reduced exposure to the sun after immigration, leading to progressive depletion of vitamin D stores, may be implicated.

A link between vitamin $\mathrm{D}$ deficiency and impaired host defence against tuberculosis has been postulated before ${ }^{25}$-indeed, fish liver oil was recommended for the treatment of tuberculosis in the eighteenth century and vitamin D was used to treat lupus vulgaris before the advent of chemotherapy. ${ }^{26}$ Furthermore, there is evidence for an immunoregulatory role for 1,25-dihydroxyvitamin $\mathrm{D}$, in both murine macrophages ${ }^{27}$ and human granulocyte-macrophage progenitor cells. ${ }^{28}$ It has been suggested that 1,25 -dihydroxyvitamin $D$ produced by $1 \alpha-$ hydroxylases present in macrophages may act in an autocrine manner to control macrophage function. ${ }^{29}$

The excess of extrapulmonary tuberculosis that we found among Asians is well known and has been attributed to the younger age of these patients, ${ }^{2}$ pulmonary tuberculosis being commoner in the older white patients. It has also been suggested that impaired host defences may be overcome by small numbers of invading mycobacteria at extrapulmonary sites, whereas immunocompetent individuals succumb to pulmonary tuberculosis only when large numbers of organisms invade the respiratory tract. ${ }^{25}$ We found that, unlike the other groups, Hindu women were more likely than men to suffer from tuberculosis. This finding may be explained by the fact that Asian women, especially Hindu women, have lower vitamin D intake and exposure to the sun than Asian men and more overt osteomalacia. ${ }^{24} \mathrm{We}$ also found that women of all groups were more likely than men to suffer from glandular tuberculosis-an effect which has not been described before, and for which we do not have a satisfactory explanation.

In conclusion, our 15 year survey of tuberculosis in south London confirms the increased susceptibility of immigrant Asians to tuberculosis, and indicates that Hindus were at particular risk. Infection was more likely to be at extrapulmonary sites in Asians than whites, and developed a mean of five years after immigration. Pulmonary tuberculosis was more common in white and Muslim men than in women. The sex ratio was reversed, however, in Hindus, who also had a strikingly increased risk of all varieties of tuberculosis, especially glandular tuberculosis. These findings could be explained by an immunodeficiency state developing after immigration to which Hindus are particularly vulnerable. We suggest that cultural factors should be considered in relation to the pathogenesis of tuberculosis in Asians. If specific nutritional deficits associated with vegetarianism do indeed produce a state of immunodeficiency and increased susceptibility to tuberculosis, these findings might be important for preventing and treating one of the world's most important public health problems, accounting for 8-10 million new cases a year worldwide. ${ }^{30}$

We thank Mrs Aruna Thakkar for her assistance in grouping the patients' names by religion, Sister Maureen Malone for help with the punched cards, and Professor H R Anderson for advice on epidemiological aspects of the study. A preliminary communication was presented to the Medical Research Society.

1 Donaldson LJ, Taylor JB. Patterns of Asian and non-Asian morbidity in hospitals. $B M J 1983 ; 286: 949-51$.

2 National survey of tuberculosis notifications in England and Wales in 1983: characteristics of disease. Tubercle 1987;68:19-32.

3 Fraser SMF. Ethnic differences in consultation rates. $B M J$ 1989;299:1220.

4 Shaunak S, Lakhani SR, Abrahams R, Maxwell JD. Differences among Asian patients. BMJ 1986;293:1169.

5 Ang L, Colston KW, Maxwell JD. Seasonal variation in serum 25-hydroxy vitamin $\mathrm{D}$ and risk of osteomalacia in adult Asians in London. Clin Sci 1988;75(suppl 19):17.

6 Morris JA, Gardner MJ. Calculating confidence intervals for relative risks (odds ratios) and standardised ratios and rates. $B M J 1988 ; 296: 1313-6$.

7 Gardner MJ, Altman DG. Confidence intervals rather than p values: estimation rather than hypothesis testing. $B M J$ p values: estimation

8 Haskey J. The ethnic minority populations of Great Britain: their size and characteristics. Population Trends 1988;54:29-31.

9 Immigrant Statistics Unit (Office of Population Censuses and Surveys). New Commonwealth and Pakistan population estimates. Population Trends 1977;9:4-7.

10 Population Statistics Division (Office of Population Censuses and Surveys). Estimating the size of the ethnic minority population in the 1980's. Population Trends 1986;44:23-7.

11 Shaw C. Latest estimates of ethnic minority populations. Population Trends 1988;51:5-8.

12 Sillitoe K. Ethnic origin: the search for a question. Population Trends 1978;13:25-30.

13 Finch PJ, Ang L, Colston K, Maxwell JD. Vegetarian diet is the major risk factor for osteomalacia in London Asians [abstract]. J Bone Min Res 1989;4:S158.

14 Runnymede Trust and Radical Statistics Race Group. Britain's black population. London: Heinemann Educational Books, 1980.

15 British Thoracic and Tuberculosis Association. Tuberculosis among immigrants related to length of residence in England and Wales. $B M J 1975 ; 2: 698-9$

16 McCarthy OR. Asian immigrant tuberculosis-the effect of visiting Asia. Br J Dis Chest 1984;78:248.

17 Gillam SJ, Jarman B, White P, Law R. Ethnic differences in consultation rates in urban general practice. $B M$ 1989;299:953-7.

18 Department of the Environment. National housing and dwellings survey. HMSO, 1978.

19 Chanarin I, Stephenson E. Vegetarian diet and cobalamin deficiency: their association with tuberculosis. J Clin Pathol 1988;41:759-62.

20 Skacel PO, Chanarin I. Impaired chemiluminescence and bacterial killing by neutrophils from patients with severe cobalamin deficiency. Br J Haematol 1983;55:203-15.

21 Lowrie DB, Andrew PW. Macrophage antimycobacterial mechanisms. Br Med Bull 1988;44:624-34.

22 Dent CE, Gupta MM. Plasma 25-hydroxyvitamin D levels during pregnancy in caucasians and in vegetarian and nonvegetarian Asians. Lancet 1975;ii:1057-60.

23 Henderson JB, Dunnigan MG, McIntosh WB, AbdulMotaal AA, Gettingby G, Glekin BM. The importance of limited exposure to ultraviolet radiation and dietary factors in the aetiology of Asian rickets: a risk-factor factors in the aetiology of Asian
model. $Q J$ Med 1987;241:413-25.

24 Hunt SP, O'Riordan JLH, Windo J, Truswell AS. Vitamin $\mathrm{D}$ status in different subgroups of British Asians. $B M$ 1976;ii:1351-4.

25 Davies PDO. A possible link between vitamin D deficiency and impaired host defence to mycobacterium tuberculosis. Tubercle 1985;66:301-6.

26 Dowling GS, Prosser-Thomas EW. Treatment of lupus vulgaris with calficerol. Lancet 1946;1:919-22.

27 Rook GAW. Role of activated macrophages in the immunopathology of tuberculosis. $\mathrm{Br}$ Med Bull 1988;44:611-23.

28 Bar-Shavit Z, Noff D, Edelstein S, Meyer M, Shibolet $S$, Goldman R. 1,25 dihydroxyvitamin D3 and the regulation of macrophage function. Calcif Tissue Int 1981;33:673-6.

29 Rook GAW. The role of vitamin D in tuberculosis. Am Rev Respir Dis 1988;138:768-70.

30 Harries AD. Tuberculosis and human immunodeficiency virus infection in developing countries. Lancet 1990 i:387-90. 